\title{
Ecological indices from environmental DNA to contrast coastal reefs under different anthropogenic pressures
}

\author{
Andrea Polanco F. ${ }^{1}$, Conor Waldock ${ }^{2}$, Thomas Keggin ${ }^{3}$, Virginie Marques ${ }^{4}$, Romane \\ Rozanski $^{5}$, Alice Valentini ${ }^{6}$, Tony Dejean ${ }^{6}$, Stephanie Manel ${ }^{7}$, Mark Vermeij ${ }^{8}$, Camille \\ Albouy $^{9}$, and Loïc Pellissier ${ }^{2}$ \\ ${ }^{1}$ Beauval Nature association \\ ${ }^{2} \mathrm{ETH}$ Zurich \\ ${ }^{3} \mathrm{ETH}$ Zürich \\ ${ }^{4}$ University of Montpellier \\ ${ }^{5}$ Ifremer Département Ressources Biologiques et Environnement \\ ${ }^{6}$ SPYGEN \\ ${ }^{7}$ Universite de Montpellier \\ ${ }^{8}$ CARMABI Research Station \\ ${ }^{9}$ DECOD (Ecosystem Dynamics and Sustainability), IFREMER, INRAE
}

February 3, 2022

\begin{abstract}
Human activities can degrade the quality of coral reefs, cause a decline in fish species richness and functional diversity and an erosion of the ecosystem services provided. Environmental DNA metabarcoding (eDNA) has been proposed as an alternative to Underwater Visual Census (UVC) to offer more rapid assessment of marine biodiversity to meet management demands for ecosystem health indices. Taxonomic information derived from sequenced eDNA can be combined with functional traits and phylogenetic positions to generate a variety of ecological indices describing ecosystem functioning. Here, we inventoried reef fish assemblages of two contrasted coastal areas of Curaçao, (i) in close proximity to the island's capital city and (ii) in a more remote area under more limited anthropogenic pressure. We sampled eDNA by filtering large volumes of sea water $(2 \mathrm{x}$ $30 \mathrm{~L}$ ) along $2 \mathrm{~km}$ boat transects, which we coupled with species ecological properties related to habitat use, trophic level and body size to investigate the difference in fish taxonomic composition, functional and phylogenetic indices recovered from eDNA metabarcoding between these two distinct coastal areas. Despite no marked difference in species richness, we found a higher phylogenetic diversity in proximity to the city, but a higher functional diversity on the more isolated reef. Composition differences between coastal areas were associated with different frequencies of reef fish families. Because of a partial reference database, eDNA only partly matched those detected with UVC, but eDNA surveys nevertheless provided rapid and robust species occupancy responses to contrasted environments. eDNA metabarcoding coupled with functional and phylogenetic diversity assessment can serve the management of coastal habitats under increasing threat from global changes.
\end{abstract}

\section{Ecological indices from environmental DNA to contrast coastal reefs under different anthro- pogenic pressures}

Andrea Polanco F. ${ }^{1}$, Conor Waldock ${ }^{2,3}$, Thomas Keggin ${ }^{2,3}$, Virginie Marques ${ }^{4,5}$, Romane Rozanski ${ }^{6}$, Alice Valentini $^{7}$, Tony Dejean ${ }^{7}$, Stéphanie Manel ${ }^{4}$, Mark Vermeij ${ }^{8}$, Camille Albouy ${ }^{6}$, Loïc Pellissier ${ }^{2,3}$

${ }^{1}$ Beauval Nature association, Saint Aignan sur Cher, France. 
${ }^{2}$ Landscape Ecology, Institute of Terrestrial Ecosystems, Department of Environmental Systems Science, ETH Zürich, Zürich, Switzerland

${ }^{3}$ Unit of Land Change Science, Swiss Federal Research Institute WSL, Birmensdorf, Switzerland

${ }^{4}$ CEFE, Univ Montpellier, CNRS, EPHE-PSL University, IRD, Univ Paul Valéry Montpellier 3, Montpellier, France

${ }^{5}$ MARBEC, Univ Montpellier, CNRS, Ifremer, IRD, Montpellier, France

${ }^{6}$ IFREMER, Unité Ecologie et Modèles pour l'Halieutique, EMH, Nantes, France

7 SPYGEN, Le Bourget-du-Lac, France

${ }^{8}$ CARMABI Foundation, Piscaderabaai z/n, P.O. Box 2090, Willemstad, Curaçao

Shared senior authorship

Correspondence should be addressed to loïc.pellissier@usys.ethz.ch and andrea.polanco@gmail.com

\begin{abstract}
Human activities can degrade the quality of coral reefs, cause a decline in fish species richness and functional diversity and an erosion of the ecosystem services provided. Environmental DNA metabarcoding (eDNA) has been proposed as an alternative to Underwater Visual Census (UVC) to offer more rapid assessment of marine biodiversity to meet management demands for ecosystem health indices. Taxonomic information derived from sequenced eDNA can be combined with functional traits and phylogenetic positions to generate a variety of ecological indices describing ecosystem functioning. Here, we inventoried reef fish assemblages of two contrasted coastal areas of Curaçao, (i) in close proximity to the island's capital city and (ii) in a more remote area under more limited anthropogenic pressure. We sampled eDNA by filtering large volumes of sea water $(2 \times 30 \mathrm{~L})$ along $2 \mathrm{~km}$ boat transects, which we coupled with species ecological properties related to habitat use, trophic level and body size to investigate the difference in fish taxonomic composition, functional and phylogenetic indices recovered from eDNA metabarcoding between these two distinct coastal areas. Despite no marked difference in species richness, we found a higher phylogenetic diversity in proximity to the city, but a higher functional diversity on the more isolated reef. Composition differences between coastal areas were associated with different frequencies of reef fish families. Because of a partial reference database, eDNA only partly matched those detected with UVC, but eDNA surveys nevertheless provided rapid and robust species occupancy responses to contrasted environments. eDNA metabarcoding coupled with functional and phylogenetic diversity assessment can serve the management of coastal habitats under increasing threat from global changes.
\end{abstract}

\title{
Key words
}

Caribbean region, coral reefs, Curaçao, environmental DNA, fish composition, functional diversity, phylogenetic diversity.

\section{Introduction}

Human activities are causing a global decline in marine biodiversity (Butchart et al. 2010). Local anthropogenic impacts on ecosystems, such as overfishing or pollution (Cinner et al. 2018), combined with global impacts including ocean acidification and climate change (Zhao et al. 2021) degrade ecosystems (De'ath et al. 2012). Coral reefs support most of the diversity of marine life on Earth (Hughes et al. 2002), which translates directly into ecosystem services upon which several billions of people depend in coastal areas (Teh et al. 2013). Fishes represent the main actors of the provision of ecosystem services (Holmlund and Hammer 1999) contributing to biomass production, food security and nutrient cycles, and generating cultural value at the core of activities such as ecotourism (Heyman et al. 2010). The decline of fish threatens tropical reef services (Hughes et al. 2003) and urges scientists, stakeholders, and industries to better monitor the change of fish diversity on tropical reefs to help in conservation and restoration decisions (Obura et al. 2019). 
Environmental governance suffers from a long delay between detecting biodiversity decline and implementing conservation measures (Wetzel et al. 2015), a delay that can be shortened by emergent monitoring technology (Polanco Fernández et al. 2021). In coastal marine ecosystems, Underwater Visual Census (UVC) is traditionally used for fish diversity assessments but are time consuming to perform (Colton and Swearer 2010). Additionally, UVCs are likely to miss the most elusive species in need of monitoring for conservation (Boussarie et al. 2018). Genetic technologies, such as eDNA metabarcoding, are rapidly developing and can now identify species assemblages from water samples containing trace DNA from organisms in the environment (Pedersen et al. 2015). When combined with a genetic reference database, eDNA metabarcoding provides an inventory of species composition in aquatic systems that often better recovers elusive and cryptic species of monitoring focus (Deiner et al. 2015; Harrison et al. 2019, Polanco Fernández et al. 2021). Studies of eDNA on coral reefs have shown a strong ability for biodiversity detection showing capacity to match inventories from traditional surveys (Sigsgaard et al. 2019; West et al. 2021; Polanco Fernández et al. 2021). Beyond inventories, eDNA could allow rapid quantification of biodiversity and ecosystem quality indices which, in combination with functional or phylogenetic information, may help monitor shifts in ecosystem processes and states (Holman et al. 2019, Marques et al. 2021).

As eDNA monitoring is sensitive to detect biodiversity responses to environmental gradients, such tools could be deployed to quantify marine biodiversity and deliver overall ecosystem indices to better monitor, manage and conserve ecosystems (Cristescu et al. 2018). Marine eDNA metabarcoding has been shown to discriminate species composition along biogeographic clines (Holman 2021, Polanco Fernández et al. 2021, West et al. 2021), or between different habitats in very localized signals (Jeunen et al. 2019). This method should thus be further able to discriminate assemblage properties in response to anthropogenic stresses (DiBattista et al. 2020). The massive amount of DNA sequence data from eDNA metabarcoding could be compounded into ecological indices, where the cumulated species-specific responses translate into measures of environmental quality (Cordier 2020). Furthermore, by combining with functional traits (e.g. including body size, trophic level) or phylogenetic information (Keck et al. 2018, Marques et al. 2021), eDNA could generate proxies of ecosystem structure and functioning more informative than those from taxonomic lists alone (D'Alessandro and Mariani 2021). The use of functional or phylogenetic indices should be first evaluated along contemporary gradients of anthropogenic pressures before future application in monitoring of assemblages (Carvalho et al. 2020).

Among bioregions with high cover of coral reefs, the Caribbean Sea harbors reefs that are degrading rapidly with a loss of $\sim 50 \%$ in just four decades as a result of anthropogenic factors (Wilkinson 2000, O'Dea et al. 2020). Coral decline is associated with a marked decrease in biodiversity and shifts in fish composition (Bellwood et al. 2004). If the present trend continues, at least $60 \%$ of Caribbean coral reefs could be lost over the next 30 years, motivating data-driven actions for improved monitoring and management (Pittman et al. 2018, Camacho et al. 2020). The decline of coral reefs has been associated with a cumulative set of anthropogenic factors, including poorer water quality from runoff and pollution, damage from tourism overuse, unsustainable fishing and climate change (Duran et al. 2018). With few exceptions (Lester et al. 2020) the lack of monitoring has limited our understanding of the relative effects of those stressors, and this gap could be filled with eDNA monitoring. Curaçao, an Island of the Lesser Antilles, has been known to support a large stretch of among the least degraded coral reefs in the Caribbean (Jackson et al. 2014). However, the decline in reef cover has increased recently because of poorer water quality, the overexploitation of fish populations, unsustainable coastal development, as well as industrial waste issues (Jackson et al. 2014). Along the coast of Curaçao, wide differences in the levels of anthropogenic pressures are nonetheless observed (Waitt institute 2017, de Bakker et al. 2016), which should be associated with contrasted fish assemblage composition either in proximity to dense human settlements or more isolated from human activities.

Here, we investigated the variation in fish taxonomic composition, as well as functional and phylogenetic indices recovered from eDNA metabarcoding along the coast of Curaçao. In particular, we compared two coastal areas with contrasted environmental and anthropogenic conditions: the first a coastal stretch in proximity to the capital, Willemstad, a dense area with nutrient rich water; and a second stretch, more isolated and generally less accessible. In each of these two coastal areas, we collected eDNA samples in 
2020, which we further compared with UVCs conducted in 2015. From this collection of data, we asked the following questions: (i) Are there differences in taxonomic ecological and phylogenetic indices between the two areas associated with contrasted environmental conditions? (ii) Do we observe similar species and assemblage composition responses across the two coastal areas recovered from eDNA and UVC? (iii) Do we observe distinct occupancy responses of species in proximity or away from densely populated areas and does it vary across fish families?

\section{Methods}

\section{Study areas}

For management purposes the coast of Curaçao has been separated into a set of coastal areas: Klein $\mathrm{Cu}-$ raçao (1), Oostpunt (2), Caracasbaai (3), Willemstad (4), Bullenbaai (5), Valentijnsbaai (6), Westpunt (7), North Shore (8). We compared the fish composition between two environmentally contrasted areas along the southern protected coast, Willemstad (4, area from Jan Thiel to Boka Sami) and Valentijnsbaai (6, area from Kaap Sint Marie to Santa Cruz). The area adjacent to Willemstad includes a port, an oil refinery and is associated with high industrial and touristic activities. This area is generally more polluted, where various pollutants can reach the sea including runoff from agriculture, industry or sewage pollution, but the high amount of resources leads to a large fish biomass (Waitt institute 2017). In contrast, Valentijnsbaai is further away from the city and contains among the highest reef quality of the entire island, receives lower visits from recreational diving and a moderate amount of fishing activities, but is also associated with lower fish biomass (Waitt institute 2017).

eDNA and UVC field sampling

In February 2020, we collected a total of 20 water samples, from 10 stations, with two filtration replicates per station, in the two investigated coastal areas. Each station consisted of a transect of $2 \mathrm{~km}$ at an overall constant distance from the coast. We recorded the GPS coordinates at the start and end of the transect, which we used to map the transect positions (Figure 1). We conducted eDNA sampling by using a filtration device composed of an Athena@ peristaltic pump (Proactive Environmental Products LLC, Bradenton,

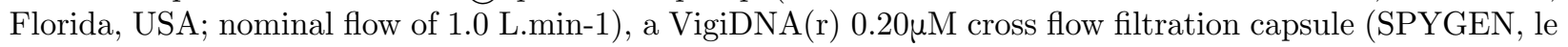
Bourget du Lac, France) and disposable sterile tubing for each filtration capsule. We performed two filtration replicates in parallel on each side of a boat, at each station, for 30 minutes corresponding to a water volume of $30 \mathrm{~L}$ of water filtered by each capsule. At the end of each filtration, the water inside the capsules was emptied, and we filled the capsules with $80 \mathrm{~mL}$ of CL1 Conservation buffer (SPYGEN, le Bourget du Lac, France) and stored at room temperature. We followed a strict contamination control protocol in both field and laboratory stages (Goldberg et al. 2016, Valentini et al. 2016). Each water sample processing included the use of disposable gloves and single-use filtration equipment.

Fish composition data from UVC were collected in 2015 by the Carmabi institute. UVC sampling sites were approximately 700 meters apart along the entire island's southern protected coast. Researchers surveyed fish composition by scuba diving at each of the sites. At each site, researchers conducted a total of five transects that were 30 meters in length. For each transect, divers quantified the number, size and identity of all fishes. All transect lines followed a constant water depth of 8 to $12 \mathrm{~m}$. Survey times per transect were limited to approximately 6 minutes per transect for a total of 30 minutes of surveys, a sampling duration equivalent to the eDNA surveys. The data from the five transects were pooled to provide the final assemblage of all fish species at each site. We selected the sites occurring in the coastal areas of focus, Willemstad and Valentijnsbaai.

\section{DNA extraction, amplification and high-throughput sequencing}

The eDNA capsules were processed at SPYGEN using a standard protocol (Polanco Fernández et al. 2021). The DNA extraction, amplification and sequencing were performed in separate dedicated rooms, equipped with positive air pressure, UV treatment and frequent air renewal. Two extractions per filter were performed following the protocol of Pont et al. (2018) and were pooled before the amplification step. After the DNA 
extraction the samples were tested for inhibition following the protocol described in Biggs et al. (2015). If the sample was considered inhibited, it was diluted 5 -fold before the amplification. DNA amplifications were performed in a final volume of $25 \mu \mathrm{L}$, using $3 \mu \mathrm{L}$ of DNA extract as the template using a teleostean primer pairs (teleo/Tele01; Valentini et al. 2016, Taberlet et al. 2018). The amplification mixture contained $1 \mathrm{U}$ of AmpliTaq Gold DNA Polymerase (Applied Biosystems, Foster City, CA), $10 \mathrm{mM}$ Tris-HCl, $50 \mathrm{mM} \mathrm{KCl}$, $2.5 \mathrm{mM} \mathrm{MgCl} 2,0.2 \mathrm{mM}$ each dNTP, $0.2 \mu \mathrm{M}$ of each primers, $4 \mu \mathrm{M}$ human blocking primer for the "teleo" primers and $0.2 \mu \mathrm{g} / \mu \mathrm{L}$ bovine serum albumin (BSA, Roche Diagnostic, Basel, Switzerland). The tags for the forward and reverse primers were identical. The PCR mixture was denatured at $95^{\circ} \mathrm{C}$ for $10 \mathrm{~min}$, followed by 50 cycles of $30 \mathrm{~s}$ at $95^{\circ} \mathrm{C}, 30 \mathrm{~s}$ at $55^{\circ} \mathrm{C}$ for teleo and finally 1 min at $72{ }^{\circ} \mathrm{C}$. Twelve replicates of PCRs were amplified per filtration. After amplification, the samples were titrated using capillary electrophoresis (QIAxcel; Qiagen GmbH) and purified using the MinElute PCR purification kit (Qiagen GmbH). Before sequencing, purified DNA was titrated again using capillary electrophoresis. We pooled the purified PCR products in equal volumes to achieve a theoretical sequencing depth of 1000,000 reads per sample. Three libraries were prepared using the MetaFast protocol. The paired-end sequencing (2x125 bp) was carried out on a MiSeq (2x125 bp, Illumina, San Diego, CA, USA) using a MiSeq Flow Cell Kit Version3 (Illumina, San Diego, CA, USA) per each library following the manufacturer's instructions. Library preparation and sequencing were performed at Fasteris (Geneva, Switzerland). Three negative extraction controls and two negative PCR controls (ultrapure water, 12 replicates) were amplified per primer pair and sequenced in parallel to the samples to monitor possible contaminants.

\section{ObiTools filtering analyses for taxonomic assignments and comparison of the two areas}

We applied a first bioinformatic workflow that optimizes the ability to detect identified taxonomic entities. The sequencing reads were processed to remove errors and analyzed using programs implemented in the ObiTools package (http://metabarcoding.org/obitools, Boyer et al. 2016) following a published protocol (Valentini et al. 2016). The forward and reverse reads were assembled using the ILLUMINAPAIREDEND program using a minimum score of 40 and retrieving only joined sequences. The reads were then assigned to each sample using the NGSFILTER software. A separate data set was created for each sample by splitting the original data set in several files using OBISPLIT. After this step, we analysed each sample individually before merging the taxon list for the final ecological analysis. Strictly identical sequences were clustered together using OBIUNIQ. Sequences shorter than $20 \mathrm{bp}$, or with occurrences lower than 10 were excluded using the OBIGREP program. The OBICLEAN program was then run within a PCR product. We discarded all sequences labelled 'internal' that correspond most likely to PCR substitutions and indel errors. Taxonomic assignment of the remaining sequences was performed using the program ECOTAG the sequences extracted from the release 142 (standard sequences) w of the European Nucleotide Archive (ENA). Taxonomic assignments were corrected as follows to be more conservative: for an identification match $>98 \%$ identity, we validated a species level, for a 96-98\% match, genus level if available and for an 90-96\% match, family level if possible. Considering the bad assignments of a few sequences to the wrong sample due to tag-jumps (Schnell et al. 2015), all sequences with a frequency of occurrence below 0.001 per taxon and per library. We further corrected for Index-Hopping (MacConaill et al., 2018) with a threshold empirically determined per sequencing batch using experimental blanks (i.e. combinations of tags not present in the libraries), for a given sequencing batch between libraries (Polanco-Fernández et al. 2021). From the taxonomic assignment recovered from the ObiTools analyses, we compared the species recovered in each area. We further compared the species recorded by eDNA with other species distribution sources, including a compiled set of species distribution maps for the Caribbean region (Robertson and Van Tassell, 2019). Differences in species recovered between the two areas using eDNA were further compared with those of the UVC transects.

\section{Taxonomic functional and phylogenetic indicators from eDNA}

Using the fish identification outputs from the ObiTools pipeline, we computed taxonomic, functional and phylogenetic indices of the structure of the fish assemblages for the two coastal areas. We collected functional traits using online databases (Fishbase.org; Froese and Pauly 2021, Robertson and Van Tassell 2015). We compiled five traits linked to diverse ecological functions: the minimum and maximum depth $(\mathrm{m})$, the 
position in the water column divided in six groups ("pelagic", "bathypelagic", "benthopelagic", "demersal", "benthic", "bathydemersal") indicating habitat, the trophic level and the maximum body size associated with food acquisition, mobility and predation functions. Sequences attributed to the species were directly associated with the corresponding functional traits. For sequences assigned at the genus or family level by ObiTools, we randomly selected from the list of the regional fish species, one species belonging to the same genus or family along with its associated traits. The random selection was performed 100 times resulting in 100 traits matrices. For each trait matrix and each coastal area, we computed the community mean of continuous trait values and the proportion for categorical traits repeated across all 100 matrices. We also computed the standard deviation of those measures. Moreover, we computed 100 distance matrices using Gower's distance which allows continuous and categorical traits (Gower 1971). We applied a Principal Coordinates Analysis $(\mathrm{PCoA})$ on each of the 100 distance matrices and computed the corresponding multivariate functional spaces (Mouchet et al. 2010). We selected the most appropriate number of axes following the framework proposed by Maire et al (2015) that evaluates the quality of the functional space based on the deviation between the original trait-based distance and the final Euclidean distance. From the PCoA, we computed the functional richness (FRic) that represents the volume of functional space defined by the convex envelope of all species in a given community (Villeger et al. 2008, Mouillot et al. 2013), the functional evenness (Feve) that represent the regularity of the distribution and relative abundance of species in functional space for a given community. We also characterized the functional divergence (Fdis) that quantifies how species diverge in their distance from the center of gravity of the functional space. As a measure of functional regularity, we computed the functional specialisation (FSpe) as the average distance of species from the barycentre of the functional space and characterised the functional distance of species from the rest of the community as a proportion of the maximum distance (Mouillot et al. 2013). We further computed the functional originality (Fori) that was calculated as the average pairwise distance between a species and its nearest-neighbor into the functional space. We produced species and functional richness accumulation curves across filtration samples by randomly selecting the samples among all possible permutations and we measured the species richness and the FRic index. To investigate the relationship between the functional richness or the species richness and the considered number of samples, we fitted a Generalized additive model.

We assessed the phylogenetic diversity components, based on a list of 100 randomised phylogenetic trees previously extracted from the phylogeny of Rabosky et al. (2018) and the taxonomic list obtained from the ObiTools assignment. For $a$ - diversity at both the Valentijnsbaai and Willemstad areas, we computed five indices to characterize the phylogenetic, richness, divergence and regularity facets (Tucker et al. 2017). We quantified the richness dimension by calculating Faith's phylogenetic diversity index (PD, Faith 1992) that corresponds to the overall amount of evolutionary history in a sampled community (Faith 1992). We computed the divergence facet using two indices, the phylogenetic Mean Pairwise Distance (MPD) corresponding to the average phylogenetic distance among species and the phylogenetic Mean Nearest Taxonomic Distance (MNTD) that measures the average phylogenetic distance among the closest relatives species within a community (Tucker et al. 2017). Then we assessed the regularity facet by calculating the variance of the phylogenetic distance among species (VPD index) and the variance of the phylogenetic distance among the closest relatives species within a community (VNTD; Tucker et al. 2017). We produced phylogenetic richness accumulation curves across filtration samples by randomly selecting the samples among all possible permutations and we measured the PD. To investigate the relationship between the phylogenetic richness and the considered number of samples, we fitted a Generalized additive model.

\section{Turnover in taxonomic functional and phylogenetic composition from eDNA}

We computed taxonomic beta diversity between samples in the two areas using the Jaccard index. To document the functional dissimilarity between the two coastal areas, we computed the functional $\beta$ diversity index and its classical decomposition into two additive components: the functional turnover and the functional nestedness resultant (Villéger et al. 2013, Baselga 2010, 2012). To document the dissimilarity in phylogenetic diversity between the two areas, we computed the UniFrac index (Lozupone and Knight 2005) and its classical decomposition in two additive components: the UniFrac Turnover (UniFracTurn) and the UniFrac Phylogenetic Diversity (UniFracPD, Leprieur et al. 2012 ). We computed the mean and the standard devia- 
tion of all the previous indices. All the $\beta$-diversity indices were computed using the "Betapart" $\mathrm{R}$ package. To visually represent the differences in eDNA composition between the sampling stations in Willemstad and Valentijnsbaai, we used a PCoA on the Jaccard distance matrix. We reported the explained deviance of each axis and mapped the ordination values in the geographic space of the PCoA. We further performed a PCoA on the UVC samples which we compared with the eDNA ordination.

\section{SWARM clustering analyses for MOTU identification}

We applied a second bioinformatic workflow to cluster sequences into taxonomic units without requiring a complete reference database to estimate richness and MOTUs composition (Marques et al. 2020). We used the sequence clustering SWARM algorithms that group multiple variants of sequences into MOTU (Molecular Operational Taxonomic Units; Mahé et al. 2014, Rognes et al. 2016). Reads were assembled using VSEARCH (Rognes et al. 2016), then demultiplex and trimmed using CUTADAPT (Martin 2013) and clustering was performed using SWARM (Mahé et al. 2014) with a minimal distance of 1 between each cluster. The clustering algorithm uses sequence similarity and abundance patterns to delineate meaningful entities, by grouping together sequence variants. Once MOTUs are generated, the most abundant sequence within each cluster is used as a representative sequence for taxonomic assignment. Then, a post-clustering curation algorithm (LULU, Frøslev et al. 2017) was applied to curate the data. The taxonomic assignment was performed using the ECOTAG program against the NCBI database. The taxonomic level of assignments was determined by the result of the ECOTAG program and the percentage of similarity between the sequences in the sample and those in the reference database. Taxonomic levels were corrected using the same thresholds as the pipeline using the ObiTools. Cleaning filters were then applied to remove sequences most likely corresponding to errors and non-specific amplifications: (i) removal of amplicons with less than 10 reads per PCR replicate, (ii) removal of the non-specific amplifications (non-fish), (iii) removal of all sequences found in only one PCR in the entire data set and (iv) removal tag-jumps and index-hopping (descibed above).

\section{Joint species distribution models to quantify occupancy response to the different coastal areas}

We used the SWARM pipeline to generate the MOTUs list in each site of the two coastal areas. From this MOTUs composition matrix, we compared the MOTUs occupancy in each area using a Hierarchical Modelling of Species Communities (HMSC; Ovaskeinen et al. 2017, Ovaskeinen and Abrego 2020): a joint species distribution model whereby latent variables help explain shared species responses to environmental variation (Warton et al. 2015). We further applied the HMSC to model the species responses from the underwater visual census (UVC) of fishes using SCUBA surveys. We applied Hierarchical Modelling of Species Communities (HMSC; Ovaskeinen et al. 2017, Ovaskeinen and Abrego 2020): a joint species distribution model whereby latent variables help explain shared species responses to environmental variation (Warton et al. 2015). The MOTU data set comprises the occurrence of 79 MOTUs in 19 samples. The UVC data set comprises the occurrence of 58 species in 32 samples. We excluded species that occurred in fewer than 5 sampling units and no more than n-2 sampling units to avoid spurious and unidentifiable environmental responses for species with few data (Ovaskeinen and Abrego 2020). For both the UVC and the MOTU, we also fitted a random effect associated with each sample to ensure latent variables (e.g., species' associations) are fitted in HMSC (Ovaskeinen and Abrego 2020). To strictly compare with the eDNA data, we both fitted a UVC model with the same number of samples as eDNA and a second model with all 32 samples. In all models, we used the sampling unit by species matrix as the response variable (i.e., the $\mathrm{n} \mathrm{x} \mathrm{n}_{\mathrm{s}}$ ' $\mathrm{Y}$ ' of HMSC; see Ovaskainen et al. 2017) propagated with species occurrence or absences (0 or 1). We used a probit regression in all analyses. We included a single fixed effect of the anthropic area as our species by covariate matrix (i.e., the $\mathrm{n} \mathrm{x} \mathrm{n}_{\mathrm{c}}$ ' $\mathrm{X}$ ' of HMSC; see Ovaskainen et al. 2017). We estimated a species-specific regression parameter to contrast their occupancy in the two areas. For the MOTU data, we further fitted a transect-level random effect to control for unexplained variation amongst sampling units (e.g., $2 \times 30 \mathrm{~L}$ water filtrations per transect). We used the R-package 'Hmsc' (Tikhonov et al. 2020) to fit our model assuming default prior distributions (Ovaskeinen and Abrego 2020). We sampled the prior distribution with four Markov Chain Monte Carlo (MCMC) chains each run for 37,500 interactions of which the first 12,500 were removed as burn-in. The chains were thinned by 100 to obtain 1000 posterior samples in total. We ensured model convergence by evaluating the potential 
scale reduction factors (e.g., Gelman and Rubin 1992). We evaluated the explanatory power of our models for each species by comparing the observed and predicted occurrences using area under receiver-operator curve (AUC; Pearce and Ferrier 2000) and Tjur's R (Tjur 2009) statistics. Due to the limited number of replicates in our study, we did not expect good predictive (out-of-sample) power and therefore only report model explanatory power (within-sample prediction).

We evaluated the proportion of MOTUs and species that exhibit positive or negative responses to anthropic areas with $95 \%$ credible intervals of coefficients non-overlapping 0 , assessed the continuity of these responses across eDNA metabarcoding MOTU and UVC data sets, and we computed the phylogenetic signal of the estimated coefficients for both eDNA and UVC. We used 100 randomised phylogenetic trees previously extracted from the phylogeny of Rabosky et al. (2018) that was pruned by both taxa lists. As the taxa list extracted from the SWARM analysis is not always at the species level, we selected one species representing the genus/family detected in the eDNA table into phylogenetic trees. Then, we calculated the mean Pagel's lambda $(\lambda)$ statistic and the mean associated $p$ value.

\section{Results}

Species detected from eDNA analysis with ObiTools

In the Willemstad area, eDNA analysis detected a total of 33 taxa assigned to species level, 47 assigned to the genus level and 44 to the family level (Table S1). Among these, 7 species, 8 genera and 7 families were unique to this area. Those species, genera and families included typical demersal species of shallow coastal waters such as the Albulidae, Gerreidae, Elopidae associated to sand soft bottoms and Achiridae, Eleotridae associated with mud soft bottoms and brackish waters (Table S1). In Valentijnsbaai area, we detected a total of 36 taxa assigned to species level, 50 assigned to the genus level and 41 to the family level (Table S1). Among these, 11 species, 8 genera and 4 families occurred exclusively in this area. Among those exclusive species, genera and families, two families were pelagic, Istiophoridae and Myliobatidae. The two remaining families were Moringuidae and Aetobatidae, comprised of demersal species associated with coastal ecosystems such as reefs and estuaries exclusively present in the area - including Moringua edwardsi and Aetobatus narinari, respectively (Table S1). In both areas, we detected the presence of species from the families Gobiidae and Apogonidae, which include the majority of crypto benthic species, an important component of reef systems (Brandl et al. 2018). One filter did not yield sufficient DNA for reliable analyses and we removed it. The eDNA analyses are presented for the 19 remaining filters.

Underwater visual census (UVC) at the stations in front of Willemstad recorded a total of 30 families, 56 genera and 99 species. Among the species in common with both methods, reef associated species such as theHalichoeres spp or Chromis multilineata were recorded by UVC and eDNA, while typical crypto benthic species such asPhaeoptyx conklini, P. pigmentaria and Priolepis hipoliti ; and pelagic species such as Carcharhinus longimanus or Acanthocybium solandri or coastal species such as Erotelis smaragdus and Mugil rubrioculus were only detected by eDNA. The detection of those species by eDNA is supported by the known occurrence of those species in Willemstad based on species range maps of the species in the Caribbean region (Supplementary Table 1). At the genus level, eleven detected genera were common in both methods and 16 were detected exclusively with eDNA. At the family level, nine detected families were common in both methods and nine families were detected exclusively with eDNA. Some reef families such Gobiidae, Labridae and Pomacentridae were recorded by both UVC and eDNA, while typical pelagic such as Clupeidae, Myctophidae and Neoscopelidae and demersal families such as Eleotridae and Mugilidae were detected by eDNA. In Valentijnsbaai area, UVC recorded a total of 33 families, 59 genera and 97 species. Reef associated species such as the Halichoeres sppor Bodianus rufus were recorded by both UVC and eDNA, while typical crypto benthic species such as Elacatinus horsti, Lophogobius cyprinoides and Oxyurichthys stigmalophius ; or classic reef top predators such as Carcharinus perezii, were only detected by eDNA. At the genus level, nine detected genera were common in both methods and 19 were detected exclusively with eDNA. At the family level, nine detected families were common in both methods and nine families were detected exclusively with eDNA. Some reef families such Apogonidae, Gobiidae and Labridae were recorded by both UVC and eDNA, while typical pelagic families such as Carcharhinidae, Clupeidae and Myctophidae 
were detected by eDNA.

\section{Differences in ecological indices between areas from eDNA}

Differences in fish composition in the eDNA samples and their association with specific functional traits drove distinct functional composition and diversity indices across the two areas. A species accumulation curve analysis showed that the two areas accumulated different levels of functional diversity (Figure 2b). For the same level of species richness all the functional indicators were higher in Valentijnsbaii except the functional divergence $\left(\mathrm{Fdiv}_{\text {Willemstad }}=0.79 \pm 0.003 ; \mathrm{Fdiv}_{\text {Valentijnsbaai }}=0.788 \pm 0.002\right.$; Figure $2 \mathrm{~b}$ ). The functional evenness $\left(\right.$ Feve Valentijnsbaai $=0.58 \pm 0.021 ;$ Feve $_{\text {Willemstad }}=0.55 \pm 0.025$; Figure $\left.2 \mathrm{~b}\right)$, the functional richness $\left(\right.$ FRic $_{\text {Valentijnsbaai }}=0.00031 \pm 3 \times 10^{-5} ;$ FRic $_{\text {Willemstad }}=0.00027 \pm 4.2 \times 10^{-5} ;$ Figure $\left.2 \mathrm{~b}\right)$ and the functional originality $\left(\right.$ Fori $_{\text {Valentijnsbaai }}=0.040 \pm 0.003$; Fori Willemstad $_{1}=0.037 \pm 0.002$; Figure $2 \mathrm{~b}$ ) were higher in Valentijnsbaai. Functional differences were due to the detection of specific species in Valentijnsbaai such as the Whitespotted eagle ray (Aetobatus narinari) and of Istiophoridae family which harbors a singular combination of traits which have a large contribution to the delimitation of the functional space.

In contrast, we found that phylogenetic diversity was systematically higher in Willemstad compared with Valentijnsbaai for all the indices computed, where phylogenetic accumulation curves showed different levels of saturation (Figure 2c). This was not caused by a higher number of taxa recovered by eDNA, which was similar across the two areas (64 taxa for Willemstad and 66 taxa for Valentijnsbaai; Figure 2b), but was mainly caused by the presence of evolutionary distinct taxa including Albulidae, Elopidae (genus Elops ), Neoscopelidae (Neoscopelus macrolepidotus ) or Engraulidae in the Willemstad area. The mean length of the tree branches represented by the unique taxa present in Willemstad was $73.68 \pm 0.66$ and was higher than the length of the unique taxa present in Valentijnsbaai $(45.38 \pm 2.35$; Figure 2c). This difference in branch length led to a higher $\mathrm{PD}$ value in Willemstad than in the Valentijnsbaai area $\left(\mathrm{PD}_{\text {Willemstad }}=5157.3\right.$ $\pm 22.32 ; \mathrm{PD}_{\text {Valentijnsbaai }}=4824.8 \pm 34.6$; $)$. The phylogenetic divergence facet characterized by the MPD or the MNTD index was also higher in Willemstad than in the Valentijnsbaai area $\left(\mathrm{MPD}_{\text {Willemstad }}=264.7\right.$ $\pm 0.08, \mathrm{MPD}_{\text {Valentijnsbaai }}=255.5 \pm 0.08$; Figure $2 \mathrm{c}$ ). Consequently, the taxa identified in Willemstad were more dispersed and presented a higher variability in distances in the phylogenetic tree (VPD $=5089.9 \pm$ $24.3)$ than the taxa identified in Valentijnsbaai $\left(\mathrm{VPD}_{\text {Willemstad }}=5089.9 \pm 24.3 \mathrm{VPD}_{\text {Valentijnsbaai }}=4657.2\right.$ \pm 22.9 ; Figure 2c).

\section{Taxonomic, functional and phylogenetic turnover from eDNA}

As regards to the $\beta$ diversity, and considering the data set obtained by applying the ObiTools pipeline, the pairwise Jaccard's dissimilarity index calculated between Willemstad and Valentijnsbaai reached a value of 0.395 meaning that the two areas present a moderate dissimilarity in species composition. The two areas had 49 taxa in common and did not share 32 among the 129 listed. The difference in taxa composition between the two regions was mainly explained by taxa turnover $\left(\beta_{\vartheta \tau v}=0.379\right)$, while the value of the taxa nestedness is low $\left(\beta_{\vartheta \nu \epsilon}=0.016\right)$. Considering phylogenetic dissimilarity, the two areas presented a moderate level of dissimilarity $(\beta$ UniFrac $=0.31)$, mainly explained by a turnover component $(\beta$ UniFracTurn $=0.27$; Figure $2 \mathrm{c})$. The functional dissimilarities between the two areas were generally low $\left(\beta_{\Phi \vartheta a S}=0.14\right)$, with a limited functional turnover $\left(\beta_{\Phi \vartheta \tau v}=0.077\right.$; Figure $\left.2 \mathrm{~b}\right)$. Applying an ordination on the MOTUs composition, we further found significant differences in composition between the two areas. The PCoA for eDNA explains a significant fraction of the total inertia (41\%) with $22.5 \%$ for the first axis and $18.5 \%$ for the second axis (Figure $3 \mathrm{a}$ and $\mathrm{b}$ ) and showed a marked difference in composition between those two coastal areas. The difference was especially marked with the three samples from the North of the island. In contrast, the two samples south of the area were more similar with Willemstad. The partial overlap of the two areas was also highlighted with the UVC (Figure 3c and d). The PCoA for UVC explains a more limited fraction of the total inertia (25.9\%) with $16.5 \%$ for the first axis and $9.4 \%$ for the second axis (Figure 3c and d).

\section{Joint species distribution models in response to a distance gradient}

The SWARM pipeline recovered a total of 196 MOTUs. Among these MOTUs, 139 could be attributed to 50 families, 103 could be attributed to 70 genera, and 44 MOTUs were assigned to species. The most 
common families were Labridae $(\mathrm{n}=12)$, Pomacentridae $(\mathrm{n}=10)$, Myctophidae $(\mathrm{n}=8)$ and $46 \%(23 / 50)$ families were represented by 1 MOTU. HMSC requires we subset this full set of data (see Methods) leaving 79 MOTUs from 34 genera in 26 families remaining in our final analyses. HMSC applied to the MOTUs revealed relatively consistent responses across species and families to the occupancy of the two coastal areas (Figure 4a). Most MOTUs showed a positive response to Willemstad (0) vs. Valentijnbaai (1) (87\%, n $=66$ of 79 MOTUs), with 14 (17\%) MOTUs with positive responses with $90 \%$ posterior estimate support in contrast to only $1(1.2 \%)$ MOTU with a negative response at this confidence level (Figure 4a). eDNA detected strong positive responses of two cryptic cardinal fish species (Phaeoptyx pigmentaria and Phaeoptyx conklini) and two pelagic top predator species (Acanthocybium solandri 'wahoo' andKatsuwonus pelamis 'skipjack tuna') to Willemstad vs. Valentijnsbaai, species absent from visual surveys. Among families with more than 3 representative MOTUs, Myctophidae (mean $\beta=0.5[2.5 \% \mathrm{CI}=-0.10,97.5 \% \mathrm{CI}=1.13]$ ) and Apogonidae $(\beta=0.45[-0.13,1.07])$ show consistent positive responses with $>90 \%$ posterior estimate support. Lutjanidae $(\beta=0.40[-0.23,1.04])$ and Scombridae $(\beta=0.32[-0.28,0.91])$ have a positive response with $>80 \%$ posterior estimate support, and Belonidae $(\beta=0.28[-0.34,0.91])$, Muraenidae $(\beta=0.26[-0.33$, $0.87])$, Clupeidae $(\beta=0.25[-0.33,0.83])$ and Mugilidae $(\beta=0.21[-0.39,0.84])$ with $>70 \%$ estimate support. In contrast to the MOTUs, joint species distribution models applied to UVC revealed more balanced but weaker occupancy responses, of fewer species $(\mathrm{n}=35)$, to the two contrasting coastal areas (Figure $4 \mathrm{~b})$. When comparing consistent sampling effort between eDNA metabarcoding and UVCs diversity estimates (19 samples each with 30 minutes survey time), we revealed weaker discrimination of species occurrence between areas using UVC compared to eDNA metabarcoding: the species-specific standard deviation of $\beta$ estimates was 1.25 times higher for species from UVC compared with MOTUs from eDNA metabarcoding (mean eDNA $=0.37$, mean $\mathrm{UVC}=0.46, \mathrm{t}=12.31, \mathrm{p}<0.001)$. We found a significant phylogenetic signal with $\lambda=0.69 \pm 0.06(\mathrm{p}=0.025 \pm 0.008)$ in the species-specific estimated coefficients, with for instance low $\beta$ parameter values for Labridae especially for the Halichoeres genus, intermediate values for Muranidae and high values for Apogonidae.

From the models applied to the UVC data, around half of the detected species show positive and negative responses to Willemstad vs. Valentijnsbaai (48\% vs. $52 \%$ of 35 species). Only 3 (8\%) species showed positive responses with $90 \%$ posterior estimate support, but $7(20 \%)$ species showed a negative response at this confidence level. Among families with more than three species detected in UVCs, no families had consistent responses with $>90 \%$ posterior estimate support. Only Lutjanidae (mean $\beta=-0.61[-1.53,0.17]$ ) had a consistent negative response with $>80 \%$ posterior estimate support. Even though the full set of UVC data were available to use in our analysis, we found only a marginal reduction in the standard deviation of $\beta$ parameters using the full data set (mean full-UVC $=0.34$, mean eDNA $=0.37, \mathrm{t}=5.99, \mathrm{p}<0.001$ ), which is equivalent to a $1.07 \mathrm{x}$ increase in parameter certainty despite an additional $1.46 \mathrm{x}$ increase in sampling units (UVC) and $\sim 390$ minutes of UVC dive time (Figure 4c). In contrast to eDNA, we found no clear phylogenetic signal for UVC transect $\beta$ parameters $\left(\lambda=6.3 \times 10^{-3} \pm 5.4 \times 10^{-6} 0.06 ; \mathrm{p}>0.05\right)$.

\section{Discussion}

A variety of human activities can impact coral reefs directly and indirectly, resulting in their degradation (Pandolfi et al. 2003) and a decline of fish diversity associated with this habitat (Graham et al. 2011). In particular, the coral cover of Curaçao has been steadily decreasing over the last decades (Gardner et al. 2005, Jackson et al. 2014) although to a lesser extent than most other islands in the Caribbean and with variations between different coastal stretches of the island (Waitt institute 2017). Here, using eDNA, we showed differences in species functional and phylogenetic compositions between two coastal areas on the Southern side of the island of Curaçao. By comparing two reef stretches under different degrees of anthropogenic pressures, we showed how eDNA combined with species features from associated databases and advanced modelling approaches can deliver ecological indices that can inform ecosystem status. Management toward the preservation of coral reef ecosystems requires monitoring approaches that can be quickly deployed in the field (Obura et al. 2019), and we demonstrated that eDNA metabarcoding provides as rich fish assemblage information as UVC in term of taxa samples, but which requires significantly less sampling time and resource in the field. Yet, remaining gaps in the reference database still limit the information provided 
by eDNA. Building on increasing evidence of the monitoring capacity of eDNA metabarcoding (DiBattista et al. 2017, West et al. 2021, Polanco Fernández et al. 2021), our study illustrates how this technique could evolve toward a general approach for the monitoring of fish communities on coral reefs.

Functional and phylogenetic characteristics are expected to offer higher dimensions of information to describe and manage ecosystems (Strecker et al. 2011). Coupling ecological indices with eDNA can provide more complete ecosystem information for coral reefs (Aglieri et al. 2020, Marques et al. 2021). As demonstrated previously with UVC (D'agata et al. 2014), we found that functional and phylogenetic indices better discriminate between the two inventoried coastal areas than taxonomic information alone. While the two reefs were similar regarding the fish species richness recovered from eDNA, we found more marked differences in their functional and phylogenetic properties. Specifically, the Valentijnsbaai reef area contained larger species such as Aetobatus narinari, more pelagic species (e.g. Thunnus sp,Istiophorus sp.) with higher trophic levels (e.g.Acanthocybium solandri ). In addition, crypto benthic species are also present such as the mimic cardinalfish (Apogon phenax) or the pale cardinalfish (Apogon planifrons) increasing the functional diversity. In contrast, Willemstad presented higher phylogenetic diversity, mainly driven by a few phylogenetically distinct species associated with soft bottoms (Albula vulpes, Elops smithi) or the water column (Anchoa colonensis ,Opisthonema oglinum ). The higher occupancy of this coastal stretch by sandy bottom and pelagic species could reflect the higher state of degradation of the coral reefs near the city. These findings suggest that environmental filtering under high levels of coastal development near Willemstad and high levels of sediments is associated with distinct fish assemblages as previously documented using UVC in Singapore (Wong et al. 2018). Hence, even if the difference between the fish assemblages in two coastal areas is subtle, the combination of eDNA metabarcoding surveys, functional and phylogenetic information allow their discrimination. Díaz-Pérez et al. (2016) proposed that the estimation of coral reef health indices should be complemented with fish community indices, to improve the accuracy of the estimated health status of coral reefs in the western Caribbean Sea. In future research, indices such as the Reef Health Index (RHI) could be complemented with multidimensional information including functional and phylogenetic indices from eDNA to inform policy makers about reef health status (Obura et al. 2019).

With the combination of eDNA metabarcoding including all MOTUs and novel statistical approaches (i.e., HMSC), we reveal a greater power of eDNA to discern species occupancy across the two coastal stretches in comparison with traditional UVCs. The application of joint species distribution models to eDNA was suggested to increase the ecological interpretation of the molecular signal (Burian et al. 2021). For similar sampling effort, eDNA metabarcoding outperformed UVCs in its capacity to identify the contrast between the two coastal areas and detected more negative responses to the more anthropogenically stressed reef area. Importantly, some of the strongest responses of MOTUs to the spatial contrast were assigned to species that are elusive, highly mobile, and cryptic. In contrast, UVCs could fail to detect the occurrence of those species, thus increasing uncertainty in their estimated responses to the environment in the distinct coastal areas. Additionally, eDNA metabarcoding generates more identifications of taxa as MOTUs than UVCs does. When we combine this richer data with HMSC, a statistical framework that reduces parameter uncertainty (via shrinkage) across similarly responding species, we can obtain greater confidence in species responses. MOTU response was further associated with a phylogenetic signal, indicating a strong distinction between clades with a positive response (Apogonidae, Murenidae) and those with more negative responses (Labridae) towards more anthropogenic stressed areas. We expect that, assuming that MOTUs are true diversity units acting as a species proxy, the generation of more data (MOTUs) to feed statistical models will lead to more robust indicators of ecological status (with a higher certainty of responses). That said, key sources of uncertainty still exist in using eDNA to assign species and a better coverage within reference databases will yield more information on the taxonomic units recovered from eDNA (Valdivia-Carrillo et al. 2021), to the point where generating MOTUs as a species proxy will become unnecessary if almost all regionally occurring species are genetically referenced.

Increasing evidence suggests that eDNA metabarcoding offers higher species detection abilities compared with traditional surveys (Polanco Fernandez et al. 2021, Valdivia-Carrillo et al. 2021), which was confirmed in our study with the greater number of MOTUs detected with eDNA (129 MOTUs) than fish species in 
UVC (120 species). We found overlap in species composition between eDNA and UVC, but also differences. While several species of relatively high abundance and easy to detect visually such as Bodianus rufus andMicrospathodon chrysurus were detected with both methods, the UVC detected more shallow reef species (e.g. Acanthurus spp), which were not detected with eDNA. The shallow reef of Curacao is characterized by a very thin stretch averaging $40 \mathrm{~m}$ and the eDNA transects were conducted slightly further away from the coast at approximately $100 \mathrm{~m}$ of distance, which could explain why some of the reef fish species were not detected. Our results suggest that the eDNA signal could be spatially localized (e.g. as in West et al. 2021), stressing the need for careful eDNA sampling to capture the entire signal of a habitat. Nevertheless, both methods of observation detected distinct fish composition between the two areas. While eDNA metabarcoding can provide a rapid inventory of species composition (Polanco Fernandez et al. 2021) and can better detect small and cryptic species, eDNA surveys cannot entirely replace UVC. In addition to generating species lists, UVC transects can provide fish ontogenetic stage, body size structure and abundance information that, at present, eDNA does not provide at all or not accurately (Rourke et al. 2021). These sources of information are key ecological indicators so that future surveys might integrate, when possible, the strengths of both survey approaches.

\section{Conclusion}

Human-related disturbances affect all marine ecosystems by disrupting major interdependent abiotic and biotic factors (Goudie 2018) and these unprecedented threats are likely to increase in the near future, stressing the need to understand and document ecosystems responses (Duarte et al. 2020). Preserving marine biodiversity via protection of species richness has been an explicit aim of management and conservation policies (Qureshi 2017). The functional and phylogenetic associations between species, however, have been gradually incorporated to conserve multiple dimensions of ecosystem diversity. We show that functional and phylogenetic diversity metrics can be derived from eDNA compositional data rapidly sampled from the field. Once the pipeline linking raw eDNA to traits and phylogeny can be automatized, the direct computation of indices will allow a fast translation into indicators that are useful for management, which can serve the monitoring of reef biodiversity over time. Our study provides the foundation for the generation of ecological indices for the long-term monitoring of marine ecosystems. Further analyses at a larger scale covering a wider range of habitats and reef types will enable these diversity patterns to be tested more broadly. Importantly, findings from this study provide further directions for the conservation of coral reefs backed by evolutionary history and trait data.

\section{Literature cited}

Aglieri, G., C. Baillie, S. Mariani, C. Cattano, A. Calo, G. Turco, D. Spatafora, A. Di Franco, M. Di Lorenzo, P. Guidetti and M. Milazzo. 2020. Environmental DNA effectively captures functional diversity of coastal fish communities. Molecular Ecology , 30 (13): 3127-3139

Baselga, A. 2010. Partitioning the turnover and nestedness components of beta diversity. Global Ecology and Biogeography , 19 (1) : 134-143.

Baselga, A. 2012. The relationship between species replacement, dissimilarity derived from nestedness and nestedness. Global Ecology and Biogeography, 21 (12) : 1223-1232. https://doi.org/10.1111/j.14668238.2011.00756.x

Bellwood, D. R., T. P. Hughes, C. Folke and M. Nystrom. 2004. Confronting the coral reef crisis. Nature, 429 (6994) : 827-833.

Biggs, J., N. Ewald, A. Valentini, C. Gaboriaud, T. Dejean, R. A. Griffiths, J. Foster, J. W Wilkinson, A. Arnell, P. Brotherton and P. Williams. 2015. Using eDNA to develop a national citizen science-based monitoring programme for the great crested newt (Triturus cristatus ). Biological Conservation, 183 : 19-28. https://doi.org/10.1016/j.biocon.2014.11.029

Boulanger, E., N. Loiseau, A. Valentini, V. Arnal, P. Boissery, T. Dejean, J. Deter, N. Guellati, F. Holon, J. B.Juhel, P. Lenfant, S. Manel and D. Mouillot. 2021. Environmental DNA metabarcoding reveals and 
unpacks a biodiversity conservation paradox in Mediterranean marine reserves. Proceedings of the Royal Society B: Biological Sciences, $\mathbf{2 8 8}$, rspb.2021.0112.

Boussarie, G., J. Bakker, O. S. Wangensteen, S. Mariani, L. Bonnin, J. B. Juhel, J. J. Kiszka, M. Kulbicki, S. Manel, W. D. Robbins, L. Vigliola and D. Mouillot. 2018. Environmental DNA illuminates the dark diversity of sharks. Science Advances , 4 (5): eaap9661.

Boyer, F., C. Mercier, A. Bonin, Y. Le Bras, P. Taberlet and E. Coissac. 2016. obitools: A unix-inspired software package for DNA metabarcoding.Molecular Ecology Resources, 16 (1) : 176-182.

Brandl, S. J., C. H. Goatley, D. R. Bellwood and L. Tornabene. 2018. The hidden half: ecology and evolution of cryptobenthic fishes on coral reefs. Biological Reviews, 93 (4) : 1846-1873.

Burian, A., Q. Mauvisseau, M. Bulling, S. Domisch, S. Qian and M. Sweet. 2021. Improving the reliability of eDNA data interpretation. Molecular Ecology Resources , 21 (5) : 1422-1433.

Butchart S. H. M., M. Walpole, B. Collen, A. van Strien, J. P. W. Scharlemann, et al. 2010. Global biodiversity: indicators of recent declines. Science 328 : 1164-1168.

Camacho, R., S. Steele, S. Challenger and M. Archibald. 2020. Status of coral reefs in Antigua \& Barbuda: using data to inform management.PeerJ , 8 , e9236.

Carvalho, F., K. A. Brown, M. P. Waller, O. H. Razafindratsima and A. Boom. 2020. Changes in functional, phylogenetic and taxonomic diversities of lowland fens under different vegetation and disturbance levels. Plant Ecology , 221 (6): 441-457.

Cinner, J. E., E. Maire, C. Huchery, M. A. MacNeil, N. A. Graham, C. Mora,. T. R. McClanahan, M. L. Barnes, J.N. Kittinger, C. C. Hicks, S. D'agata, A. S. Hoey, G. G. Gurney, D. A. Feary, I. D. Williams, M. Kulbicki, L.Vigliola, L. Wantiez, G. J. Edgar, R. D. Stuart-Smith, S. A. Sandin, A. Green, M. J. Hardt, M. Beger, A. M. Friedlander, S. K. Wilson, E. Brokovich, A. J. Brooks, J. J. Cruz-Motta, D. J. Booth, P. Chabanet, C. Gough, M. Tupper, S. C. A. Ferse, U. R. Sumaila, S. Pardede and D. Mouillot. 2018. Gravity of human impacts mediates coral reef conservation gains. Proceedings of the National Academy of Sciences , 115 (27): E6116-E6125.

Colton, M. A., and S. E. Swearer. 2010. A comparison of two survey methods: differences between underwater visual census and baited remote underwater video. Marine Ecology Progress Series , 400 : 19-36.

Cordier, T. 2020. Bacterial communities' taxonomic and functional turnovers both accurately predict marine benthic ecological quality status. Environmental DNA , 2 (2): 175-183.

Cristescu, M. E. and P. D. Hebert. 2018. Uses and misuses of environmental DNA in biodiversity science and conservation. Annual Review of Ecology, Evolution, and Systematics , 49 : 209-230.

D'agata, S., D. Mouillot, M. Kulbicki, S. Andrefouet, D. R. Bellwood, J. E. Cinner, P. F. Cowman, M. Kronen, S. Pinca and L. Vigliola, 2014. Human-mediated loss of phylogenetic and functional diversity in coral reef fishes. Current Biology, 24 (5): 555-560.

D'Alessandro, S. and S. Mariani. 2021. Sifting environmental DNA metabarcoding data sets for rapid reconstruction of marine food webs. Fish and Fisheries .

De'ath, G., K.E. Fabricius, H. Sweatman and M. Puotinen. 2012. The 27-year decline of coral cover on the Great Barrier Reef and its causes.Proceedings of the National Academy of Sciences, 109 : 17995-17999.

De Bakker, D. M., E. H. Meesters, R. P. Bak, G. Nieuwland and F. C. Van Duyl. 2016. Long-term shifts in coral communities on shallow to deep reef slopes of Curacao and Bonaire: are there any winners?.Frontiers in Marine Science, 3 : 247.

Deiner, K., J. C. Walser, E. Machler and F. Altermatt. 2015. Choice of capture and extraction methods affect detection of freshwater biodiversity from environmental DNA. Biological Conservation, 183 : 53-63. 
Diaz-Perez, L., F. A. Rodriguez-Zaragoza, M. Ortiz, A. L. Cupul-Magana, J. D. Carriquiry, E. Rios-Jara,. A. P. Rodriguez-Troncoso and M. C. Garcia-Rivas. 2016. Coral reef health indices versus the biological, ecological and functional diversity of fish and coral assemblages in the Caribbean Sea. PloS one, 11 (8): $\mathrm{e} 0161812$.

DiBattista, J. D., D. J. Coker, T. H. Sinclair-Taylor, M. Stat, M. L. Berumen and M. Bunce. 2017. Assessing the utility of eDNA as a tool to survey reef-fish communities in the Red Sea. Coral Reefs ,36 (4): 1245-1252.

DiBattista, J. D., J. D. Reimer, M. Stat, G. D. Masucci, P. Biondi, M. De Brauwer, S. P. Wilkinson, A. A. Chariton and M. Bunce. 2020. Environmental DNA can act as a biodiversity barometer of anthropogenic pressures in coastal ecosystems. Scientific reports, $\mathbf{1 0}$ (1): 1-15.

Duarte, C. M., S. Agusti, E. Barbier, G. L. Britten, J. C. Castilla, J. P. Gattuso, R.W. Fulweiler, T.P. Hughes, N. Knowlton, C. E. Lovelock, H. K. Lotze, M. Predragovic, E. Poloczanska, C. Roberts and B. Worm, 2020. Rebuilding marine life. Nature, 580 (7801): 39-51.

Duran, A., A. A. Shantz, D. E. Burkepile, L. Collado-Vides, V. M. Ferrer, L. Palma, A. Ramos and P. Gonzalez-Diaz, 2018. Fishing, pollution, climate change, and the long-term decline of coral reefs off Havana, Cuba. Bulletin of Marine Science, 94 (2): 213-228.

Faith, D. P. 1992. Conservation evaluation and phylogenetic diversity. Biological conservation, 61(1), 1-10.

Froese, R. and D. Pauly. Editors. 2021. FishBase. World Wide Web electronic publication. www.fishbase.org, version $(06 / 2021)$.

Froslev, T. G., R. Kjoller, H. H. Bruun, R. Ejrnaes, A. K. Brunbjerg, C. Pietroni and A. J. Hansen. 2017. Algorithm for post-clustering curation of DNA amplicon data yields reliable biodiversity estimates. Nature communications, 8 (1): 1-11.

Gardner, T. A., I. M. Cote, J. A. Gill, A. Grant and A. R Watkinson. 2005. Hurricanes and Caribbean coral reefs: impacts, recovery patterns, and role in long-term decline. Ecology, 86 (1): 174-184.

Gelman, A., and D. B. Rubin. 1992. Inference from iterative simulation using multiple sequences. Statistical science, 7 (4): 457-472.

Goudie, A. S. 2018. Human impact on the natural environment. John Wiley \& Sons.

Gower, J. C. 1971. General coefficient of similarity and some of its properties. Biometrics, 27 : 857-871. https://doi.org/10.2307/2528823

Graham, N. A., P. Chabanet R. D. Evans, S. Jennings, Y. Letourneur, M. Aaron MacNeil, T. R. McClanahan, M. C. Ohman, N.V. Polunin and S. K. Wilson. 2011. Extinction vulnerability of coral reef fishes.Ecology letters, 14 (4): 341-348.

Goldberg, C. S., C. R. Turner, K. Deiner, K. E. Klymus, P. F. Thomsen, M. A. Murphy, S. F. Spear, A. McKee, S. J. Oyler-McCance, R. S. Cornman and M. B. Laramie. 2016. Critical considerations for the application of environmental DNA methods to detect aquatic species. Methods in Ecology and Evolution, 7 (11): 1299-1307

Harrison, J. B., J. M. Sunday and S. M. Rogers. 2019. Predicting the fate of eDNA in the environment and implications for studying biodiversity. Proceedings of the Royal Society B ,286 (1915): 20191409.

Heyman, W. D., L. M. Carr and P. S. Lobel. 2010. Diver ecotourism and disturbance to reef fish spawning aggregations: it is better to be disturbed than to be dead. Marine Ecology Progress Series ,419 : 201-210.

Holman, L. E., M. de Bruyn, S. Creer, G. Carvalho, J. Robidart and M. Rius. 2019. Detection of introduced and resident marine species using environmental DNA metabarcoding of sediment and water. Scientific reports, $\mathbf{9}(1): 1-10$. 
Holman, L.E., M. de Bruyn, S. Creer, G. Carvalho, J. Robidart and M. Rius. 2021. Animals, protists and bacteria share marine biogeographic patterns. Nature Ecology \&3 Evolution, 5 (6): 738-746.

Holmlund, C. M. And M. Hammer. 1999. Ecosystem services generated by fish populations. Ecological economics , 29 (2): 253-268.

Hughes T. P., A.H. Baird, D.R. Bellwood, M. Card, S.R. Connolly, C. Folke, R. Grosberg, O. HoeghGuldberg, J. B. Jackson, J. Kleypasand and J. M. Lough. 2003 Climate change, human impacts, and the resilience of coral reefs. Science 301 :929-933

Hughes, T. P., D. R. Bellwood and S. R. Connolly. 2002. Biodiversity hotspots, centres of endemicity, and the conservation of coral reefs.Ecology Letters , 5 (6): 775-784.

Jackson, J. B. C., M. K. Donovan, K. L. Cramer and V. V. Lam. 2014. Status and trends of Caribbean coral reefs. Global Coral Reef Monitoring Network, IUCN, Gland, Switzerland, 1970-2012.

Jeunen, G. J., M. Knapp, H. G. Spencer, M. D. Lamare, H. R. Taylor, M. Stat, M. Bunce and N. J. Gemmell. 2019. Environmental DNA (eDNA) metabarcoding reveals strong discrimination among diverse marine habitats connected by water movement. Molecular Ecology Resources , 19 (2): 426-438.

Keck, F., V. Vasselon, F. Rimet, A. Bouchez and M. Kahlert. 2018. Boosting DNA metabarcoding for biomonitoring with phylogenetic estimation of operational taxonomic units' ecological profiles.Molecular Ecology Resources , 18 (6): 1299-1309.

Leprieur F., C. Albouy, J. de Bortoli, P. F. Cowman, D. R. Bellwood and D. Mouillot. 2012. Quantifying phylogenetic beta diversity: Distinguishing between "true" turnover of lineages and phylogenetic diversity gradients. PLoS One. 7 (8).

Lester, S. E., A. Rassweiler, S. J. McCoy, A. K. Dubel, M. K. Donovan, M. W. Miller, B.I. Ruttenberg, J. F. Samhouri and M. E. Hay. 2020. Caribbean reefs of the Anthropocene: Variance in ecosystem metrics indicates bright spots on coral depauperate reefs. Global change biology, 26 (9): 4785-4799.

Lozupone, C. and R. Knight. 2005. UniFrac: a new phylogenetic method for comparing microbial communities. Applied and environmental microbiology , 71 (12): 8228-8235.

Mahe, F., T. Rognes, C. Quince, C. de Vargas and M. Dunthorn. 2014. Swarm: robust and fast clustering method for amplicon-based studies.PeerJ , 2, e593.

Maire, E., G. Grenouillet, S. Brosse and S. Villeger. 2015. How many dimensions are needed to accurately assess functional diversity? A pragmatic approach for assessing the quality of functional spaces. Global Ecology and Biogeography , 24 (6): 728-740.

Marques, V., P. Castagne, A. P. Fernandez, G. H. Borrero-Perez, R. Hocde, P. E, Guerin, J.B. Juhel, L. Velez, N. Loiseau, T.B. Letessier, S. Bessudo, A. Valentini, T. Dejean, D. Mouillot, L. Pellissier and S. Villeger. 2021. Use of environmental DNA in assessment of fish functional and phylogenetic diversity. Conservation Biology .

Marques, V., P. E. Guerin, M. Rocle, A. Valentini, S. Manel, D. Mouillot and T. Dejean. 2020. Blind assessment of vertebrate taxonomic diversity across spatial scales by clustering environmental DNA metabarcoding sequences. Ecography, 43 (12): 1779-1790.

Martin, M. 2013. Cutadapt removes adapter sequences from high-throughput sequencing reads 2011. EMBnet.Journal , 17 (1):10. https://doi.org/10.14806/ej.17.1.200

Mouchet, M. A., S. Villeger, N. W. Mason, and D. Mouillot. 2010. Functional diversity measures: an overview of their redundancy and their ability to discriminate community assembly rules. Functional Ecology , 24 (4), 867-876. 
Mouillot, D., N. A. Graham, S. Villeger, N. W. Mason and D. R, Bellwood. 2013. A functional approach reveals community responses to disturbances. Trends in ecology $\mathscr{E}$ evolution, 28 (3): 167-177.

O'Dea, A., M. Lepore, A. H. Altieri, M. Chan, J. M. Morales-Saldana, N. H. Munoz,. J.M. Pandolfi, M.A. Toscano, J.X. Zhao and E. M. Dillon, 2020. Defining variation in pre-human ecosystems can guide conservation: An example from a Caribbean coral reef. Scientific reports ,10 (1): 1-10.

Obura, D. O., G. Aeby, N. Amornthammarong, W. Appeltans, N. Bax, J. Bishop, R.E. Brainard, S. Chan, P. Fletcher, T.A. Gordon, L. Gramer and S. Wongbusarakum. 2019. Coral reef monitoring, reef assessment technologies, and ecosystem-based management. Frontiers in Marine Science , $6: 580$.

Ovaskainen, O. and N. Abrego. 2020. Joint Species Distribution Modelling: With Applications in R. Ecol. Biodivers. Conserv. Cambridge University Press, Cambridge.

Ovaskainen, O., G. Tikhonov, A. Norberg, F. Guillaume Blanchet, L. Duan, D. Dunson, T. Roslin, and N. Abrego. 2017. How to make more out of community data? A conceptual framework and its implementation as models and software. Ecology Letters , 20 : 561-576.

Pandolfi, J. M., R. H. Bradbury, E. Sala, T. P. Hughes, K. A. Bjorndal, R. G. Cooke, D. McArdle, L. McClenachan, M. J. Newman, G. Paredes, R.R Warner and J. B Jackson. 2003. Global trajectories of the long-term decline of coral reef ecosystems. Science, 301 (5635): 955-958.

Pedersen, M. W., S. Overballe-Petersen, L. Ermini, C. D. Sarkissian, J. Haile, M. Hellstrom, J. Spens, P.F. Thomsen, K. Bohmann, E. Cappellini, I.B. Schnell and E. Willerslev. 2015. Ancient and modern environmental DNA. Philosophical Transactions of the Royal Society B: Biological Sciences , 370 (1660): 20130383.

Pearce, J. And S. Ferrier. 2000. An evaluation of alternative algorithms for fitting species distribution models using logistic regression.Ecological Modelling , 128: 127- 147.

Pittman, S. J., M. Poti, C. F. Jeffrey, L. M. Kracker and A. Mabrouk. 2018. Decision support framework for the prioritization of coral reefs in the US Virgin Islands. Ecological Informatics , 47 : 26-34.

Polanco Fernandez, A., V. Marques, F. Fopp, J. B. Juhel, G. H. Borrero-Perez, M. C. Cheutin, T. Dejean, J.D. Gonzalez Corredor, A. Acosta-Chaparro, R. Hocde, D. Eme, C. Albouy and L. Pellissier. 2020. Comparing environmental DNA metabarcoding and underwater visual census to monitor tropical reef fishes. Environmental DNA,3 (1):142-156.

Pont, D., M. Rocle, A. Valentini, R. Civade, P. Jean, A. Maire, N. Roset, M. Schabuss, H. Zornig and T. Dejean. 2018. Environmental DNA reveals quantitative patterns of fish biodiversity in large rivers despite its downstream transportation. Scientific Reports ,8 (1): 1-13.

Qureshi, W. A. 2017. Marine Biodiversity Conservation: The International Legal Framework and Challenges. Houston Journal of International Law, $40: 845$.

Rabosky, D. L., J. Chang, P. O. Title, P. F. Cowman, L. Sallan, M. Friedman, K. Kaschner, C. Garilao, T. J. Near, M. Coll, and M. E. Alfaro. 2018. An inverse latitudinal gradient in speciation rate for marine fishes. Nature, $\mathbf{5 5 9}$ (7714): 392-395.

Robertson, D. R. And J. Van Tassell. 2015. Shorefishes of the Greater Caribbean: online information system. Version 1.0 Smithsonian Tropical Research Institute, Balboa, Panama.

Rognes, T., T. Flouri, B. Nichols, C. Quince and F. Mahe. 2016. VSEARCH: A versatile open source tool for metagenomics. PeerJ , 4, e2584. https://doi.org/10.7717/peerj.2584

Rourke, M. L., A. M. Fowler, J. M. Hughes, M. K. Broadhurst, J. D. DiBattista, S. Fielder, J. Wilkes Walburn and E. M. Furlan. 2021. Environmental DNA (eDNA) as a tool for assessing fish biomass: A review of approaches and future considerations for resource surveys. Environmental DNA . 
Schnell, I. B., R. Sollmann, S. Calvignac-Spencer, M. E. Siddall, W. Y. Douglas, A. Wilting, and M. T. P. Gilbert. 2015. iDNA from terrestrial haematophagous leeches as a wildlife surveying and monitoring tool-prospects, pitfalls and avenues to be developed. Frontiers in Zoology , 12 (1): 24. https://doi.org/10.1186/s12983-015-0115-z

Sigsgaard, E. E., F. Torquato, T. G. Froslev, A. B. Moore, J. M. Sorensen, P. Range, R. Ben-Hamadou, S. S. Bach, P. R. Moller and P. F. Thomsen. 2019. Using vertebrate environmental DNA from seawater in biomonitoring of marine habitats. Conservation Biology, 34 (3): 697-710. https://doi.org/10.1111/cobi.13437

Strecker, A. L., J. D. Olden, J. B. Whittier and C. P. Paukert. 2011. Defining conservation priorities for freshwater fishes according to taxonomic, functional, and phylogenetic diversity. Ecological Applications, 21 (8): 3002-3013.

Teh L. S. L., L. C. L. Teh and U. R. Sumaila 2013. A global estimate of the number of coral reef fishers. PLoS One 8 :e65397.

Tikhonov, G., O. H. Opedal, N. Abrego, A. Lehikoinen, M. M. de Jonge, J. Oksanen and O. Ovaskainen. 2020. Joint species distribution modelling with the r-package Hmsc. Methods in ecology and evolution ,11 (3): $442-447$.

Tjur, T. 2009. Coefficients of determination in logistic regression models-A new proposal: The coefficient of discrimination. The American Statistician, 63 (4): 366-372.

Tucker, C.M., M.W. Cadotte, S.B. Carvalho, T.J. Davies, S. Ferrier, S.A. Fritz, R. Grenyer, M.R. Helmus, L.S. Jin, A.O. Mooers, S. Pavoine, O. Purschke, D.W. Redding, D.F. Rosauer, M. Winter and F. Mazel. 2017. A guide to phylogenetic metrics for conservation, community ecology and macroecology. Biological Reviews, 92 : 698-715.https://doi.org/10.1111/brv.12252

Taberlet, P., A. Bonin, E. Coissac and L. Zinger. 2018. Environmental DNA: For biodiversity research and monitoring . Oxford University Press, Oxford.

Valentini, A., P. Taberlet, C. Miaud, R. Civade, J. Herder, P. F. Thomsen, E. Bellemain, A. Besnard, E. Coissac, F. Boyer, C. Gaboriaud, P. Jean, N. Poulet, N. Roset, G. H. Copp, P. Geniez, D. Pont, C. Argillier, J.-M. Baudoin and T. Dejean. 2016. Next-generation monitoring of aquatic biodiversity using environmental DNA metabarcoding. Molecular Ecology , 25 (4): 929-942. https://doi.org/10.1111/mec.13428

Valdivia-Carrillo, T., A. Rocha-Olivares, H. Reyes-Bonilla, , J. F. Dominguez-Contreras and A. MunguiaVega. 2021. Integrating eDNA metabarcoding and simultaneous underwater visual surveys to describe complex fish communities in a marine biodiversity hotspot.Molecular Ecology Resources , 21 (5): 1558-1574.

Villeger, S., G. Grenouillet and S. Brosse. 2013. Decomposing functional $\beta$-diversity. Global Ecology and Biogeography, 22 : 671-681.https://doi.org/10.1111/geb.12021

Villéger, S., N.W.H. Mason and D. Mouillot. 2008. New multidimensional functional diversity indices for a multifaceted framework in functional ecology. Ecology, 89 : 2290-2301.https://doi.org/10.1890/07-1206.1

WAITT institute. 2017. The state of Curaçao's coral reefs. Marine scientific assessment.

Warton, D.I., F.G. Blanchet, R.B.O. Hara, O. Ovaskainen, S. Taskinen, S.C. Walker and F. K. Hui. 2015. So Many Variables : Joint Modeling in Community Ecology. Trends in ecology \& evolution, 30 : 766-779.

West, K., M. J. Travers, M. Stat, E. S. Harvey, Z. T. Richards, J. D. DiBattista, S. J. Newman, A. Harry, C. L. Skepper, M. Heydenrych and M. Bunce. 2021. Large-scale eDNA metabarcoding survey reveals marine biogeographic break and transitions over tropical north-western Australia. Diversity and Distributions .

Wetzel, F. T., H. Saarenmaa, E. Regan, C. S. Martin, P. Mergen, L. Smirnova, E.O. Tuama, F.A. Garcia Camacho, A. Hoffmann, K. Vohland and C. L. Hauser. 2015. The roles and contributions of Biodiversity Observation Networks (BONs) in better tracking progress to 2020 biodiversity targets: a European case study. Biodiversity ,16 (2-3): 137-149. 
Wilkinson, C. 2000. Status of coral reefs of the world: 2000. Australian Institute of Marine Science.

Wong, J. S., Y. S. Chan, C, L. Ng, K. P. Tun, E. S. Darling and D. Huang. 2018. Comparing patterns of taxonomic, functional and phylogenetic diversity in reef coral communities. Coral Reefs ,37 (3): 737-750.

Zhao, H., M. Yuan, M. Strokal, H. C. Wu, X. Liu, A. Murk, C. Kroeze and R. Osinga. 2021. Impacts of nitrogen pollution on corals in the context of global climate change and potential strategies to conserve coral reefs. Science of the Total Environment, 145017.

\section{Figures legends}

Figure 1. Area of eDNA and UVC surveys along the southern coast of Curacao. The main sampling areas were the coastal stretch of Valentijnsbaai in the more remote northern part of the island and the coastal stretch along the main city of Willemstad in proximity to industrial and other anthropogenic activities.

Figure 2. Spider plots of indices, richness accumulation curves and boxplot of beta diversity showing the comparison between both the Willemstad (purple) and Valentijnsbaai (green) sampling sites. The first column (a) shows the community-level weighted means of trait values (TL: Trophic Level; BS: Body Size), the taxa richness accumulation curves and the taxonomic? dissimilarity. The second column (b) shows the main functional diversity indicators (FRic: functional richness; Fdiv: functional divergence; Fori: functional originality; Fspe: functional specialisation; TR: taxa richness), the functional richness accumulation curves and the functional ? dissimilarity. The third column (c) shows the main phylogenetic indicators (PD: phylogenetic diversity; MPD: Mean Pairwise Distance; VPD: Variance of the Pairwise Distance ;MNTD: Mean Nearest Taxonomic Distance; VNTD: Variance of the Nearest Taxonomic Distance), the phylogenetic richness accumulation curves and the phylogenetic dissimilarity.

Figure 3. Compositional differences (PCoA) (a) from the presence absence matrix between the eDNA samples (b) and from the UVC transects between both the Willemstad (purple) and Valentijnsbaai (green) areas. The maps indicate the geographic positions of the samples with the corresponding colours.

Figure 4. Individual species responses to the coastal area, where positive coefficient indicate greater signal of occupancy in Valentijnsbaai compared with Willemstadt. Upper panels related to species responses revealed through eDNA metabarcoding (a), whereas lower panels indicate species responses revealed through UVC transects (b). Uncertainty in the estimated species parameters with eDNA, UVC with the same number of samples as eDNA and UVC with all samples is provided (c).

\section{Data Accessibilty Statement}

Data used during this study will be stored and freely available for consultation at Envidat after acceptance of the manuscript.

\section{Competing Interests Statement}

All authors declare that there is no conflict of interest regarding the publication of this article.

\section{Author Contributions section}

LP, CA, and APF jointly designed this study, LP, CA, APF, CW and TK participated in the field work. LP, CA, APF, CW, TK, VM, RR and AV analyzed the data. All the authors APF, CW, TK, VM, TD, SM, CA and LP contributed to writing the manuscript.

\section{Acknowledgements}

All samples were collected on Curacao under the collecting permits (Government reference: 2012/ 48584) of the Curacaoan Government provided to CARMABI (Piscaderabaai 00000, Willemstad, Curacao; a registered CITES Institution under Code AN001). The authors acknowledge CARMABI of Curacao for their assistance, especially Oscar Frans and Alcides Martinez for the sampling effort.

\section{Figures}




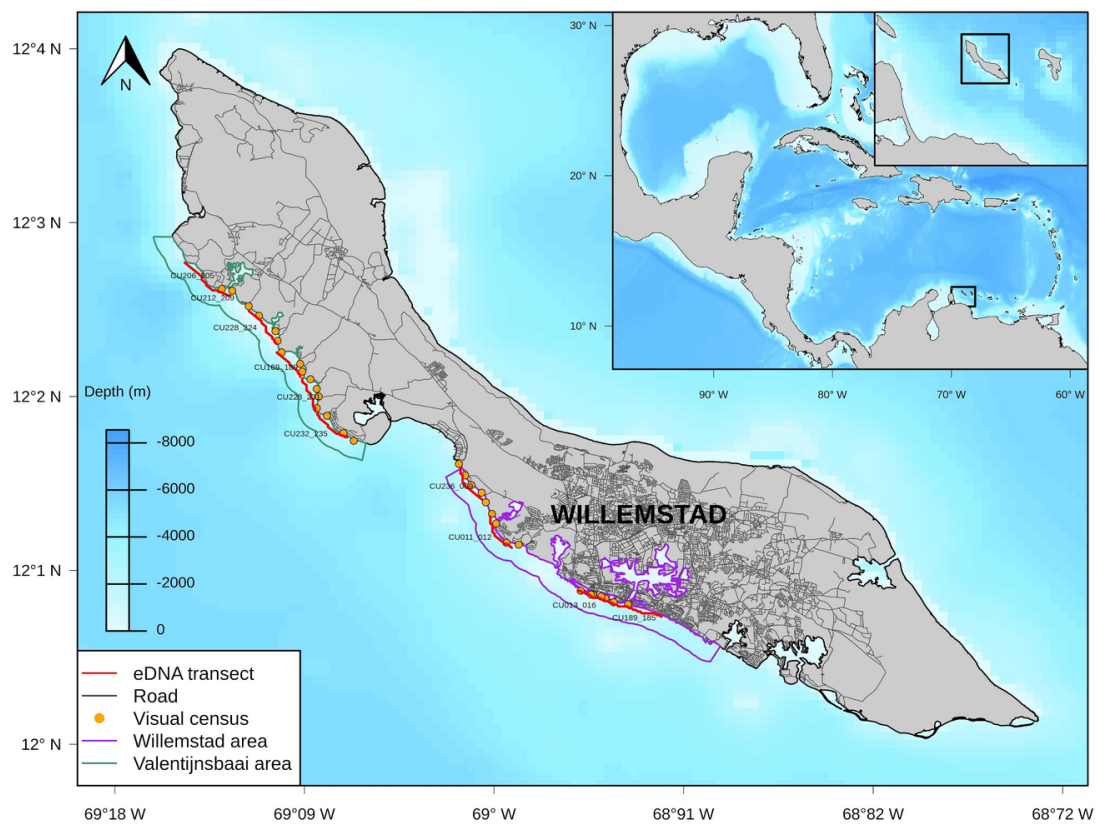

Figure 1. Area of eDNA and UVC surveys along the southern coast of Curaçao. The main sampling areas were the coastal stretch of Valentijnsbaai in the more remote northern part of the island and the coastal stretch along the main city of Willemstad in proximity to industrial and other anthropogenic activities.

a)
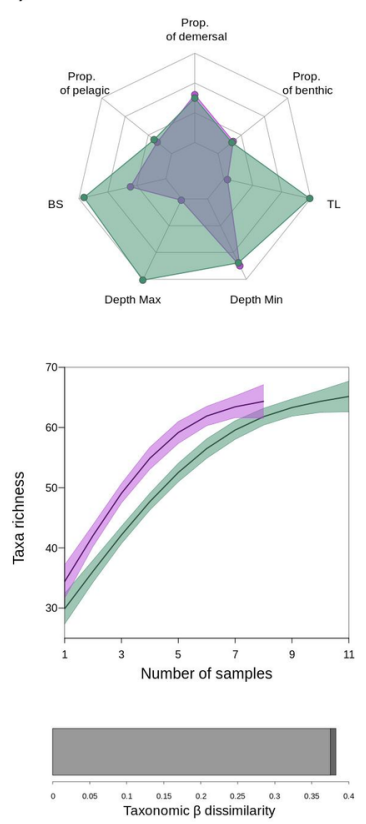

b)
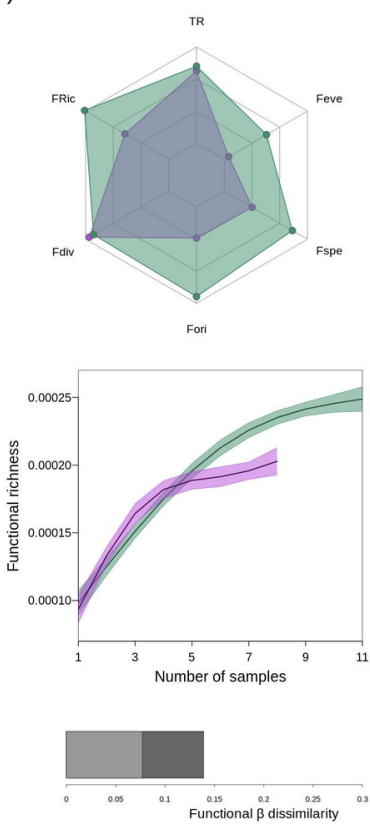

c)
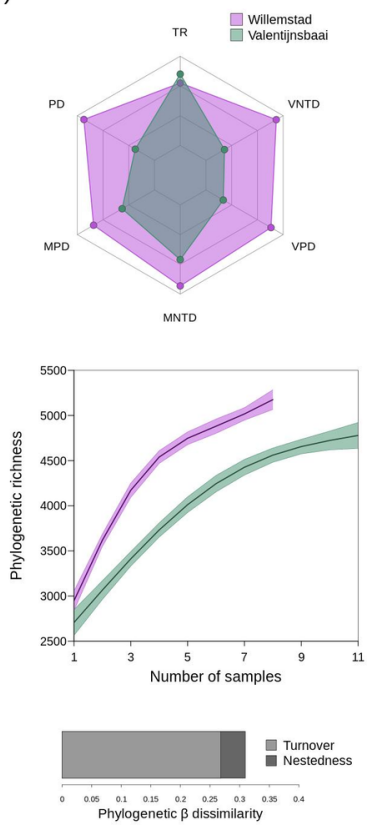

Figure 2. Spider plots of indices, richness accumulation curves and boxplot of beta diversity showing the comparison between both the Willemstad (purple) and Valentijnsbaai (green) sampling sites. The first 
column (a) shows the community-level weighted means of trait values (TL: Trophic Level; BS: Body Size), the taxa richness accumulation curves and the taxonomic? dissimilarity. The second column (b) shows the main functional diversity indicators (FRic: functional richness; Fdiv: functional divergence; Fori: functional originality; Fspe: functional specialisation; TR: taxa richness), the functional richness accumulation curves and the functional ? dissimilarity. The third column (c) shows the main phylogenetic indicators (PD: phylogenetic diversity; MPD: Mean Pairwise Distance; VPD: Variance of the Pairwise Distance ;MNTD: Mean Nearest Taxonomic Distance; VNTD: Variance of the Nearest Taxonomic Distance), the phylogenetic richness accumulation curves and the phylogenetic dissimilarity.
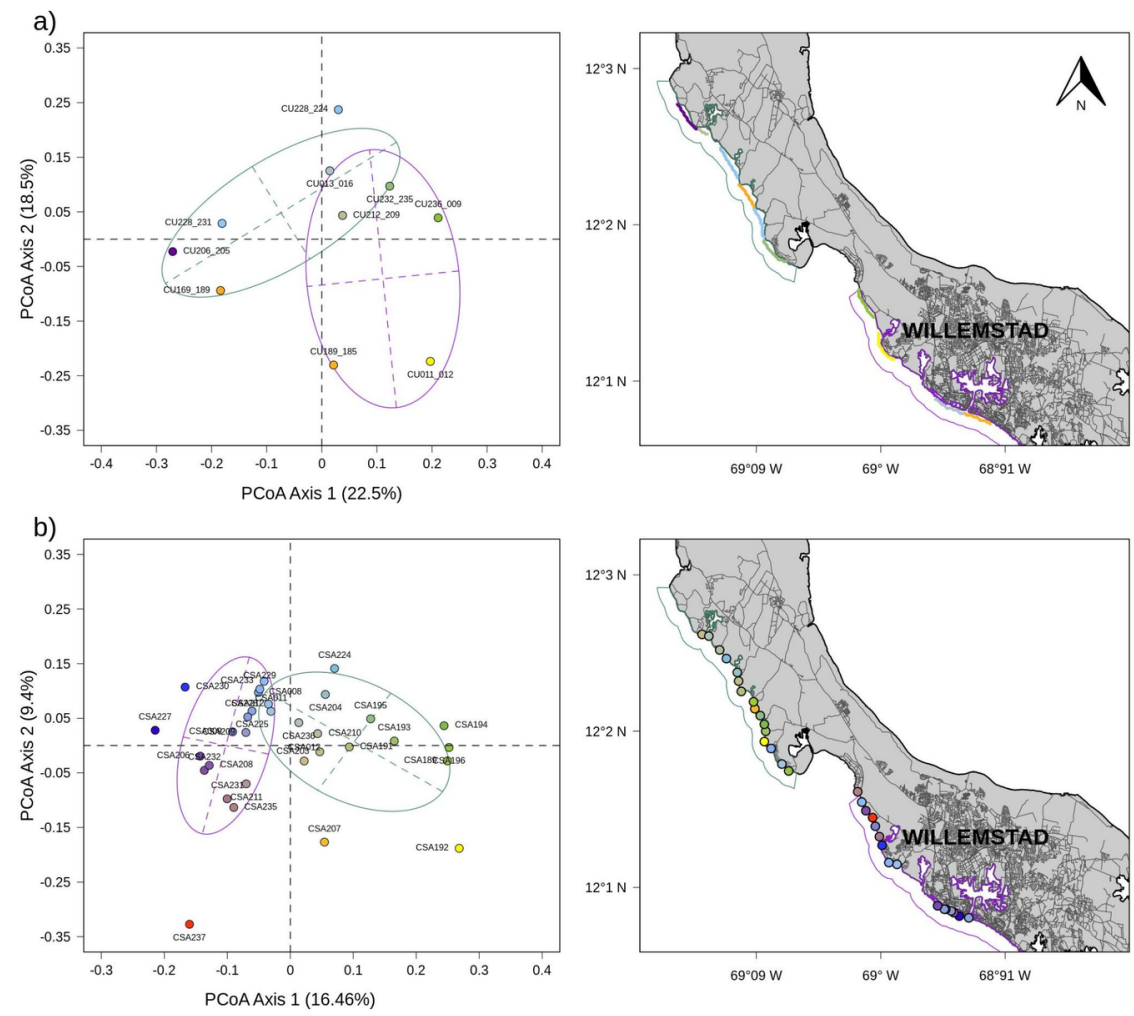

Figure 3. Compositional differences (PCoA) (a) from the presence absence matrix between the eDNA samples (b) and from the UVC transects between both the Willemstad (purple) and Valentijnsbaai (green) areas. The maps indicate the geographic positions of the samples with the corresponding colours. 

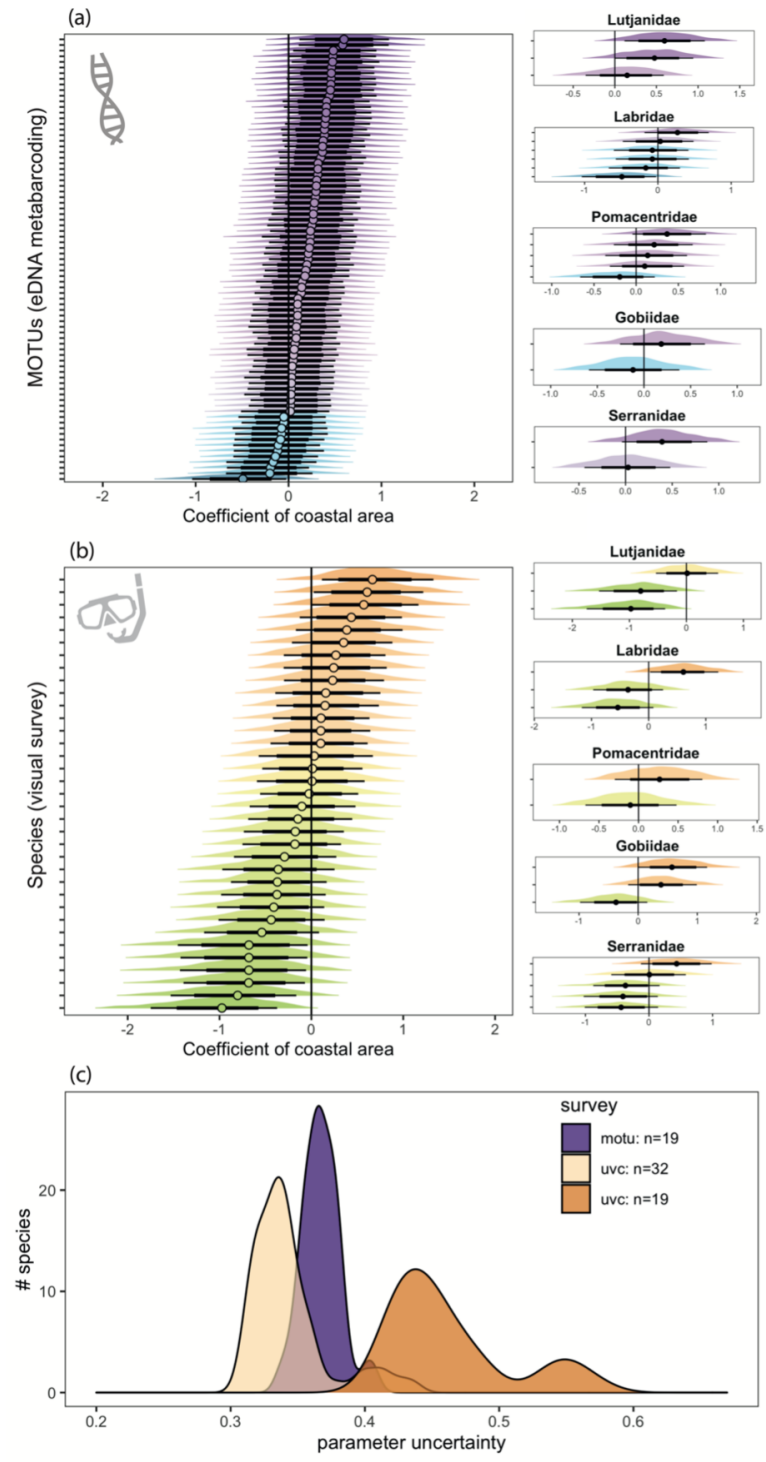

Figure 4. Individual species responses to the coastal area, where positive coefficient indicate greater signal of occupancy in Valentijnsbaai compared with Willemstadt. Upper panels related to species responses revealed through eDNA metabarcoding (a), whereas lower panels indicate species responses revealed through UVC transects (b). Uncertainty in the estimated species parameters with eDNA, UVC with the same number of samples as eDNA and UVC with all samples is provided (c). 